\title{
Autoxidation of Lipids in Parchment
}

Matija Strlič ${ }^{1 *}$, Irena Kralj Cigić ${ }^{2}$, Ira Rabin ${ }^{3}$, Jana Kolar ${ }^{4}$, Boris Pihlar $^{2}$, May Cassar ${ }^{1}$

${ }^{1}$ Centre for Sustainable Heritage, The Bartlett School of Graduate Studies, University College of London, Gower Street (Torrington Place site), London WCIE 6BT, United Kingdom

${ }^{2}$ University of Ljubljana, Faculty of Chemistry and Chemical Technology, Aškerčeva 5, SI-1000

Ljubljana, Slovenia

${ }^{3}$ Federal Institute for Materials Research and Testing, Unter den Eichen 44-46, 12203 Berlin, Germany

${ }^{4}$ Morana RTD d.o.o., Oslica 1b, SI-1295 Ivančna Gorica, Slovenia

*corresponding author: m.strlic@ucl.ac.uk

\begin{abstract}
Historic parchment is a macromolecular material, which is complex due to its natural origin, inhomogeneity of the skin structure, unknown environmental history and potential localised degradation. Most research into its stability has so far focussed on thermal and structural methods of analyses.
\end{abstract}

Using gas-chromatographic analysis of the atmosphere surrounding parchment during oxidation, we provide the experimental evidence on the production of volatile aldehydes, which can be the products of lipid autoxidation. Oxidation of parchment with different aldehyde emissions was additionally followed in situ using chemiluminometry and the same techniques were used to 
M. Strlič, I. Kralj Cigić, I. Rabin, J. Kolar, B. Pihlar, M. Cassar: "Autoxidation of Lipids in Parchment", Polym. Degrad. Stab. 94 (2009) 886-890

evaluate the oxidation of differently delipidised parchment. It was shown that the production of peroxides and the emission of aldehydes from the material decrease with lower lipid content. Building on this evidence, we can conclude that the presence of lipids (either initially present in the skin or resulting from conservation intervention) leads to oxidative degradation of collagen and that the non-destructive analysis of the emission of volatiles could be used as a quick tool for evaluation of parchment stability.

\section{Keywords}

Collagen, Carbonyl compounds, GC-MS, Chemiluminescence

\section{Introduction}

Parchment is a unique, historically exceptionally important material. From the Middle Ages, its production from goat, sheep or calf skins traditionally involved removing hair in lime, washing in water, thinning and drying under tension. In ancient times, unhairing was achieved mostly by soaking in liquors containing vegetable infusions [1]. Though there are no extensive studies on the correlation between the lipid content of parchment and materials involved in the processing of the skins, there are results indicating higher proportion of fats in non-limed parchment [2]. The product is a predominantly collagenous material, however, the production process sometimes involved rubbing with a variety of materials to improve the appearance and writability. It was well known that adhesion of ink onto parchment depends on thorough removal of animal fats from the parchment and for this purpose, lime, chalk or ash was applied [3]. Due to its historical importance, the durability of parchment is of particular interest. However, studies of historic materials are difficult due to the unknown environmental history and 
M. Strlič, I. Kralj Cigić, I. Rabin, J. Kolar, B. Pihlar, M. Cassar: "Autoxidation of Lipids in Parchment", Polym. Degrad. Stab. 94 (2009) 886-890

production methods. In addition, being made from animal skins, parchment has a very uneven composition and structure. Using micro-samples, methods of thermal analysis are often used to study parchment degradation [4-6], focusing on thermal degradation of collagen. Recently, however, the idea has been put forward that lipids in parchment might have a role in long-term parchment degradation and the correlation between lipid content and collagen damage evaluated using XRD was demonstrated on a number of historic parchment samples [7].

There is a compelling body of evidence that in living organisms, oxidation of proteins is associated with a variety of disorders, from Alzheimer's disease, rheumatoid arthritis, diabetes, sepsis, chronic renal failure, to respiratory distress syndrome [8]. The evidence for oxidative stress can be found in the increase of the content of carbonyl groups in protein macromolecules, but also in the content of low-molecular weight carbonyl compounds present in the substrate. 'Carbonyl stress' is associated mainly with autoxidation of carbohydrates or lipids [9]. In living organisms, the latter process is characterised especially by production of malondialdehyde (MDA) and hydroxynonenal, although it is known that lipid autoxidation leads to a large variety of low-molecular weight products [10]. Oxidation of proteins then proceeds through either direct reaction with reactive oxygen species produced in the process of lipid autoxidation (hydroxyl radical, peroxyl radical, hydrogen peroxide etc.) or through reactions with reactive carbonyl species, which lead to the production of correspondingly modified amino acids, e.g. MDAlysine. Other possibilities for oxidation of cellular proteins include transition-metal mediated oxidation [11] and photoxidation [12].

Based on the research done on biological systems, it seems that for the degradation of parchment at moderate temperatures, lipid autoxidation-mediated oxidation of collagen might be very relevant, however, experimental evidence still needs to be presented. Separation and 
M. Strlič, I. Kralj Cigić, I. Rabin, J. Kolar, B. Pihlar, M. Cassar: "Autoxidation of Lipids in Parchment", Polym. Degrad. Stab. 94 (2009) 886-890

identification of aldehydes in parchment could be performed using liquid chromatography or even gas chromatography, considering that low-molar mass aldehydes are volatile. In order to provide evidence for the presence of reactive oxygen species in parchment, however, chemiluminometry is a very appropriate technique.

The emission of light as a consequence of oxidation has long been used in studies of degradation of polymeric materials [13] and has also extensively been used in studies of historic paper [14], but not for many other historic materials of organic origin. Additionally, there are only a few studies of chemiluminescence (CL) of proteinaceous materials. Abrusci et al. studied chemiluminescence of gelatine and showed that light emission depends on the content of hydrogen peroxide, on macromolecular mobility and on the bloom value [15]. Millington et al., on the other hand, focussed primarily on wool proteins, but also used collagen and a number of amino acids for comparison [16]. Both found similar CL phenomena in $\mathrm{N}_{2}$ and $\mathrm{O}_{2}$ atmospheres, and the dependence of CL on the glass transition temperature, $\mathrm{T}_{\mathrm{g}}$.

In our study, we investigated the content of volatile aldehydes present in parchment using solidphase micro-extraction and GC/MS to provide an indication of lipid autoxidation taking place during low-temperature degradation of parchment. In order to investigate oxidation phenomena in situ, we employed chemiluminometry of differently delipidised parchment. Our results provide experimental confirmation of the importance of lipid-autoxidation in low-temperature degradation of parchment. 


\section{Experimental}

\section{Materials}

Two types of calf skin parchment (A, B) were used, sourced through suppliers of conservation materials. The sample containing more lipids was extracted with hexane using a Soxhlet apparatus for $0 \min (\mathrm{A} 0$, only immersed in hexane and dried), $15 \min (\mathrm{A} 1), 60 \min (\mathrm{A} 2), 90 \mathrm{~min}$ (A3) and $150 \mathrm{~min}(\mathrm{~A} 4)$. After extraction, the samples were dried in vacuum and equilibrated at room temperature in darkness for several days.

\section{Solid phase micro extraction (SPME)}

In order to investigate the emissions from oxidised parchment, we subjected the individual samples to a pre-oxidation treatment $\left(80{ }^{\circ} \mathrm{C}\right.$ for $\left.90 \mathrm{~h}\right)$ in a $1.5-\mathrm{mL}$ glass vial. Headspace sampling was performed from the vials using SPME fibres (Supelco, Bellefonte) with a DVB/CAR/PDMS stationary phase, thickness $50 / 30 \mu \mathrm{m}$. Before each sampling, the fibre was pre-conditioned at $250{ }^{\circ} \mathrm{C}$ for $30 \mathrm{~min}$.

Gas chromatography-mass spectrometry (GC-MS)

An Agilent Technologies 7890 gas chromatograph, coupled to an Agilent Technologies 5975C quadrupole mass spectrometer equipped with a Gerstel cooled injection system CIS 4 and a $60-\mathrm{m}$ Restek RTX-20 column, I.D. $0.25 \mathrm{~mm}$ and $1-\mu \mathrm{m}$ stationary phase thickness were used. The mobile phase used was helium (99.999\%) at a flow of $0.9 \mathrm{~mL} \mathrm{~min}^{-1}$. The following oven temperature programme was used: $1 \mathrm{~min}$ at $40{ }^{\circ} \mathrm{C}$, then heating to $280{ }^{\circ} \mathrm{C}$ at the rate of $10.0{ }^{\circ} \mathrm{C} \mathrm{min}^{-1}$, after which the temperature was kept constant for $40 \mathrm{~min}$. 
M. Strlič, I. Kralj Cigić, I. Rabin, J. Kolar, B. Pihlar, M. Cassar: "Autoxidation of Lipids in Parchment", Polym. Degrad. Stab. 94 (2009) 886-890

Ionisation was performed using standard EI mode applying $70 \mathrm{eV}$ at $230{ }^{\circ} \mathrm{C}$. The interface was heated to $270{ }^{\circ} \mathrm{C}$ and the quadrupole mass analyser to $150{ }^{\circ} \mathrm{C}$. The detection was initially performed using total ion current, and afterwards the identification of the most abundant volatiles was performed using the NIST mass spectra library.

\section{Chemiluminometry $(C L)$}

Chemiluminometric experiments were performed using the Lumipol 2 chemiluminometer, manufactured at the Polymer Institute of the Slovak Academy of Sciences, Bratislava, Slovakia. A sample (9 mm diameter) was placed onto an aluminium pan placed on the oven in the sample compartment. Dynamic ('ramp') experiments (temperature increased from $40{ }^{\circ} \mathrm{C}$ to $220{ }^{\circ} \mathrm{C}$ at the heating rate of $2.5^{\circ} \mathrm{C} \mathrm{min}^{-1}$ ) were carried out. The measurements were performed in a nitrogen atmosphere, maintaining a flow of $3 \mathrm{~L} \mathrm{~h}^{-1}$. Pre-oxidation of samples was performed in a flow of oxygen at $80{ }^{\circ} \mathrm{C}$ for $120 \mathrm{~min}$, following which the temperature was cooled down to $40{ }^{\circ} \mathrm{C}$ and the atmosphere switched to $\mathrm{N}_{2}$. After a 15-min period of annealing, the dynamic experiment in $\mathrm{N}_{2}$ was performed in order to follow the formation of peroxide species during oxidation.

\section{Results and discussion}

In order to examine the presence of aldehydes emitted from the parchment samples during atmospheric oxidation, we subjected them to an oxidation pre-treatment, which involved heating at $80{ }^{\circ} \mathrm{C}$ for $90 \mathrm{~h}$ in closed vials. Following this step, sampling of the emitted volatiles using SPME fibres was performed for $1 \mathrm{~h}$ at room temperature. The desorption of volatiles was performed in the $\mathrm{GC}$ injector at $250{ }^{\circ} \mathrm{C}$ and chromatographic separation and identification was performed. The majority of VOCs emitted from the parchments were acyclic aliphatic aldehydes 
M. Strlič, I. Kralj Cigić, I. Rabin, J. Kolar, B. Pihlar, M. Cassar: "Autoxidation of Lipids in Parchment”, Polym. Degrad. Stab. 94 (2009) 886-890

with carbon chains of different length (C4-C9). The relative amount of the emitted volatile aldehydes and ketones from parchment $\mathrm{A}$ is much more intensive than that from parchment $\mathrm{B}$ (Fig. 1). In Table 1, we list the identified compounds emitted from the two materials and it is evident that most are aldehydes and ketones, the majority of which are linear chain molecules, which could be derived from lipid autoxidation. Especially in sample A (Fig. 1), 6-methyl-2heptanone $\left(t_{R}=16.9\right)$ is a particularly abundant species.

Table 1: Identified volatile carbonyl compounds emitted from parchment during oxidation with atmospheric oxygen.
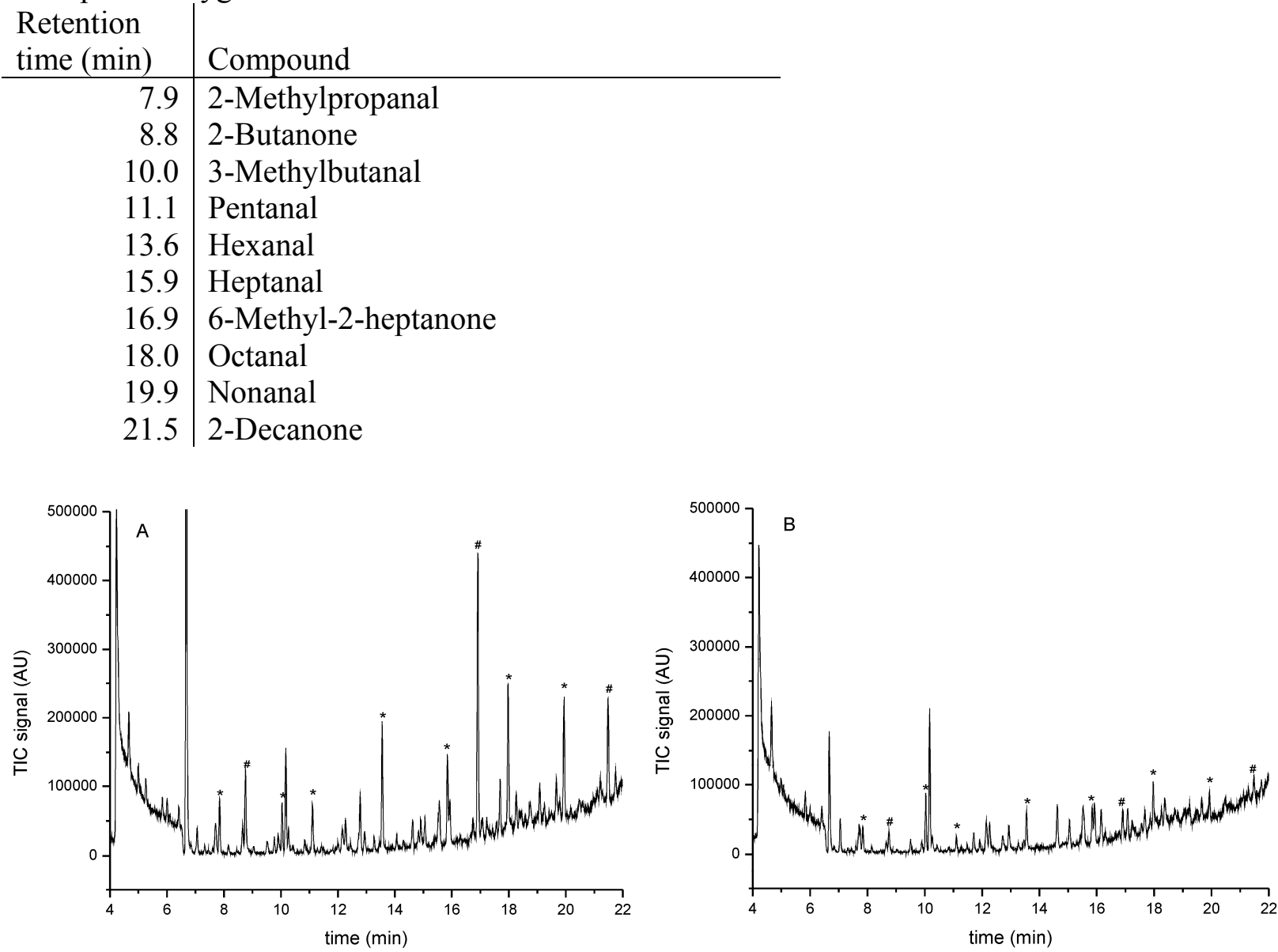

Fig. 1: Total ion chromatograms (TICs) of volatiles emitted from two different parchment samples. GC-MS analyses were performed after SPME sampling at room temperature. Aldehydes are marked with * and ketones with \#. 
M. Strlič, I. Kralj Cigić, I. Rabin, J. Kolar, B. Pihlar, M. Cassar: "Autoxidation of Lipids in Parchment", Polym. Degrad. Stab. 94 (2009) 886-890

Chemiluminescence (CL) of the parchments was followed in a dynamic atmosphere of nitrogen at a constant flow. The samples were gradually heated from 40 to $200{ }^{\circ} \mathrm{C}$ at a rate of $2.5^{\circ} \mathrm{C} \mathrm{min}{ }^{-1}$. In Fig. 2, we can observe CL curves exhibiting distinct features, which can be associated with the emission of aldehydes and ketones: parchment A emits a higher amount of carbonyl compounds while parchment B exhibited a very low emission (Fig. 1). The CL experiment with the non-pre-oxidised parchment shows an almost monotonous increase of intensity until a peak is reached at $170-180^{\circ} \mathrm{C}$. This peak is present in both oxidised and nonoxidised samples and its origin is at present the subject of further studies.

The CL peak at $140-150{ }^{\circ} \mathrm{C}$ is also of great interest: it appears as a prominent feature after oxidation of both parchments. In both proteinaceous and cellulosic materials, this peak is associated with peroxide content $[14,16]$, the peroxides having been introduced during the 2-h pre-oxidation at $80{ }^{\circ} \mathrm{C}$ in oxygen. It is evident that the peak, and CL emission in general, is higher in the sample emitting more carbonyl compounds.

The presence of these compounds could be regarded as an indication of oxidative stress in parchment, similar to the often discussed carbonyl stress in biological systems. On the other hand, aldehydes can also initiate autoxidative processes [13] and thus increase damage associated with lipid autoxidation. The emission of large quantities of aldehydes from parchment could therefore be regarded as an indication of more extensive degradation and since it can be performed quickly and in a non-destructive manner, could prove to be an attractive option for assessment of material stability. 


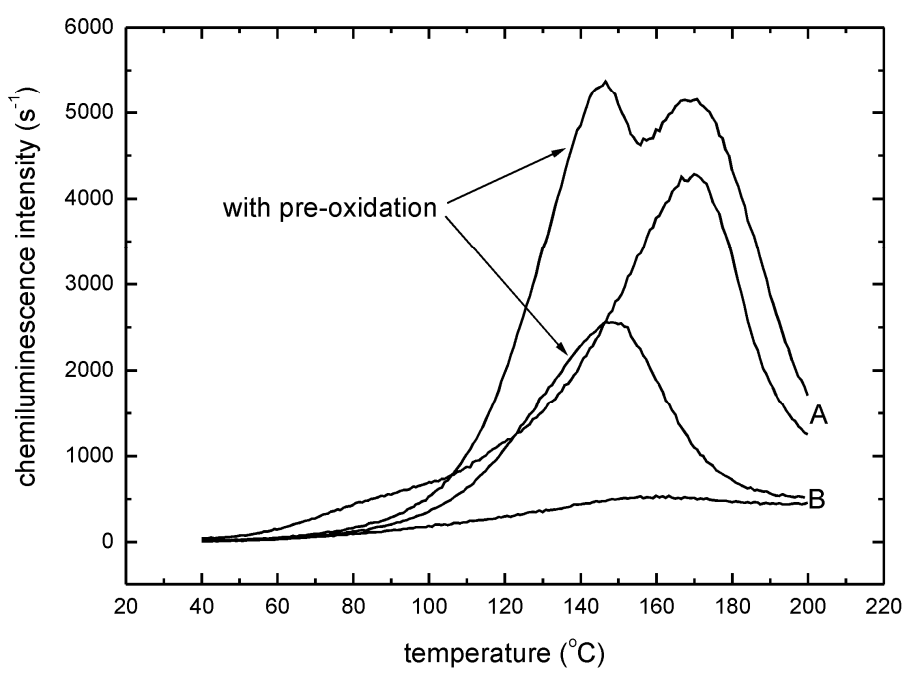

Fig. 2: Dynamic chemiluminometric experiments with parchments in $\mathrm{N}_{2}$ atmosphere with $\left(\mathrm{O}_{2}\right.$, $120 \mathrm{~min}$ ) and without pre-oxidation. Sample A with high emission, sample B with low emission of carbonyl compounds.

During autoxidation, the accumulation and stability of peroxide species in a macromolecular matrix depends on a number of parameters, chemical (macromolecular chain composition, presence of impurities etc.), physical (macromolecular movement, diffusion of gases through the macromolecular matrix etc.) and environmental (temperature, humidity, light etc.) $[13,17]$. The CL studies so far performed on collagenous materials support the view that in collagen, peroxide species are not very short-lived and this can be observed using chemiluminometry. However, the fact that parchment is a particularly non-homogenous material from both the chemical and structural perspective, considerably contributes to difficulties with interpretation of CL emission. The experiments described in Fig. 2 indicate that the emission of carbonyl compounds from parchment can be associated with lipid content. In order to provide the experimental evidence, we performed a series of experiments with partly delipidised parchment samples. We achieved this through Soxhlet extraction of a modern parchment for different periods of time, from 0 
(washing by immersion) to $150 \mathrm{~min}$. Subsequently, the samples were thoroughly dried in vacuum and re-equilibrated at room conditions.

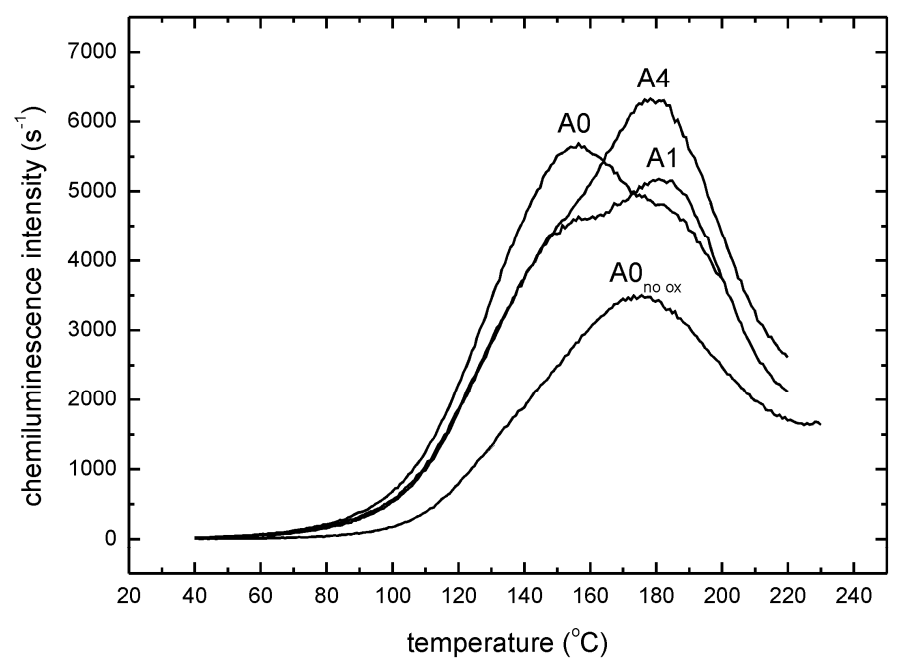

Fig. 3: Dynamic chemiluminometric experiments with parchments in $\mathrm{N}_{2}$ atmosphere after Soxhlet extraction with hexane. Duration of extraction: A0 - $0 \mathrm{~min}, \mathrm{~A} 1-15 \mathrm{~min}, \mathrm{~A} 4-150 \mathrm{~min}$, samples pre-oxidised in $\mathrm{O}_{2}$ atmosphere for $120 \mathrm{~min}$ at $80{ }^{\circ} \mathrm{C}$. Sample D was not pre-oxidised.

With samples prepared in this way, a series of CL experiments were performed, in which the samples were first pre-oxidised for $120 \mathrm{~min}$ at $80{ }^{\circ} \mathrm{C}$ in a flow of oxygen, then annealed in nitrogen at $40{ }^{\circ} \mathrm{C}$ for $15 \mathrm{~min}$ and finally, a ramp experiment in $\mathrm{N}_{2}$ atmosphere was performed. In Fig. 3, we can observe that the intensity of the peroxide peak at $140-150{ }^{\circ} \mathrm{C}$ decreases with the duration of extraction, until it is barely present, i.e. the case of sample extracted for $150 \mathrm{~min}$ (A4 in Fig. 3). The sample exposed to no pre-oxidation ( $\mathrm{A} 0_{\text {no ox }}$ in Fig. 3), exhibits no peroxide peak and in general shows lower intensity of CL emission.

By deconvolution of the curves in Fig. 3 into Gaussian peaks, we can plot the areas of the peroxide peaks versus duration of Soxhlet extraction (Fig. 4). It is evident that removal of lipids 
from the macromolecular material significantly decreases the amount of peroxides following a pre-oxidation treatment.

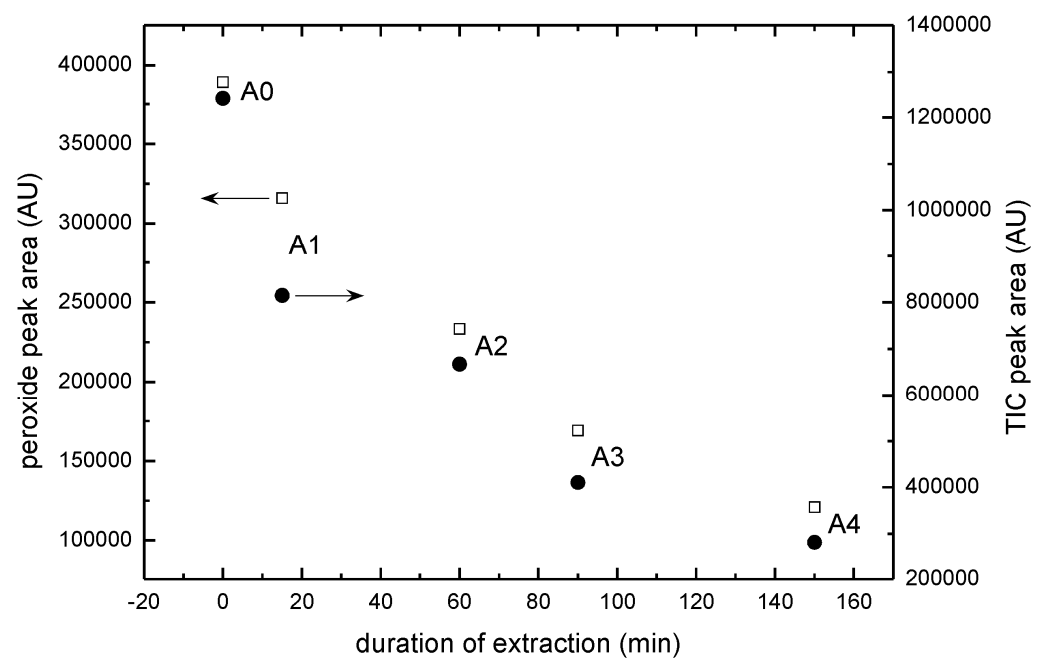

Fig. 4: Area of the peroxide peak of pre-oxidised parchment samples $\left(\mathrm{O}_{2}\right.$ atmosphere for $120 \mathrm{~min}$ at $80{ }^{\circ} \mathrm{C}$ ), cf. Fig. 3, and total ion chromatographic peak area of the most abundant carbonyl compound 6-methyl-2-heptanone in dependence of duration of extraction: A0 - 0 min, A1 - 15 min, A2 - 60 min, A3 - 90 min, A4 - 150 min.

In addition, we performed pre-oxidation experiments $\left(80{ }^{\circ} \mathrm{C}\right.$ for $90 \mathrm{~h}$ in closed vials) with the delipidised samples and subsequently analysed the emitted volatiles using SPME-GC/MS. Semiquantitative determination was performed for the most abundant carbonyl compound 6-methyl-2heptanone. From Fig. 4, it is evident that the emission of aldehydes and ketones, and the emission of chemiluminescence during atmospheric oxidation correlate very well.

Following the above experiments, we can conclude that both the amount of peroxides and the amount of carbonyl compounds can be linked to the lipid content of parchment, which is washed out during extraction with hexane (max. loss of mass was $1.7 \%$ ). Autoxidation of lipids is a relatively well researched subject [10] and decomposition of peroxides can proceed via a number of pathways including production of oxygen-containing free radicals. In parchment, their 
M. Strlič, I. Kralj Cigić, I. Rabin, J. Kolar, B. Pihlar, M. Cassar: "Autoxidation of Lipids in Parchment", Polym. Degrad. Stab. 94 (2009) 886-890

migration from the point of production is possible and oxidative damage to collagen can be the consequence. On the other hand, migration of aldehydes, themselves products of lipid autoxidation, and their further oxidation may lead to infectious spreading of oxidation of parchment with a high lipid content. Our work thus demonstrates the missing link between degradation of the collagenous phase and lipid autoxidation, and the emission of volatile aldehydes and ketones as its consequence.

\section{Conclusions}

Using SPME-GC/MS we have shown that oxidation of lipids in parchment leads to emission of volatile carbonyl compounds, which are well-known to be products of lipid autoxidation. Using chemiluminometry, we have also shown that peroxides are formed during oxidation of parchment and that a higher content of lipids leads to more extensive formation of peroxides. Based on this, we argue that autoxidation of lipids in parchment leads to degradation of the collagenous phase. The origin of lipids in parchment could be either intrinsic (i.e. originating from the skin) or extrinsic (i.e. introduced during production or even conservation intervention). The occasional use of unsaturated oils for parchment preservation should thus be discouraged. On the other hand, emissions of volatile aldehydes could be an important indicator of parchment instability - especially since the analyses can be performed in a non-destructive manner, which is essential for objects of high historic and artistic value. Further work is needed to better understand light emission from parchment and oxidation of this highly interesting proteinaceous material. 


\section{Acknowledgements}

Financial support of the Slovenian Research Agency, Programme No. P1-0153 and project BI-

RO 016 (2008-2009), is gratefully acknowledged.

\section{Literature}

1. Reed R. Ancient Skins, Parchments and Leathers. New York: Seminar Press, 1972.

2. Ginell W. Report on Dead Sea Scrolls studies. Los Angeles: Getty Conservation Institute, 1993.

3. Reed R. The Nature and Making of Parchment, Leeds:Elmete Press, 1975.

4. Odlyha M, Cohen NS, Foster GM, Aliev A, Verdonck E, Grady D. Dynamic mechanical analysis (DMA), 13C solid state NMR and microthermomechanical studies of historical parchment, J Therm Anal Calorim 2003;71:939-951.

5. Della Gatta G, Badea E, Ceccarelli R, Usacheva T, Masic A, Collucia S. Assessment of damage in old parchment by DSC and SEM, J Therm Anal Calorim 2005;82:637-649.

6. Popescu C, Budrugea P., Wortmann F-J, Miu L, Demco DE, Baias M. Assessment of collagen-based materials which are supports of cultural and historical objects, Polym Degrad Stab 2008;93,976-982.

7. Ghioni C, Hiller JC, Kennedy CJ, Aliev AE, Odlyha M, Boulton M, Wess TJ, Evidence of a distinct lipid fraction in historical parchments: a potential role in degradation?, J Lip Res 2005;46,2726-2734.

8. Dalle-Donne I, Rossi R, Giustarini D, Milzani A, Colombo R. Protein carbonyl groups as biomarkers of oxidative stress, Clin. Chim. Acta 2003;329,23-38.

9. Inagi R, Miyata T. Oxidative Protein Damage with Carbohydrates and Lipids in Uremia: 'Carbonyl Stress', Blood Purif 1999;17,95-98.

10. Spiteller G, Kern W, Spiteller P. Investigation of aldehydic lipid peroxidation products by gas chromatography-mass spectrometry, J Chromatogr A 1999;843,29-98.

11. Stadtman ER. Protein oxidation and aging, Science 1992;257,1220-1224.

12. Kato Y, Uchida K, Kawakishi S. Oxidative degradation of collagen and its model peptide by ultraviolet irradiation, J Agric Food Chem 1992;40,373-379.

13. Zlatkevich L, editor. Luminescence techniques in solid-state polymer research. New York: Marcel Dekker; 1989.

14. Strlič M, Kolar J, editors. Ageing and stabilisation of paper. Ljubljana: National and University Library; 2005.

15. Abrusci C, Martin-Gonzalez A, Del Amo A, Catalina F, Bosch P, Corrales T. Chemiluminescence study of commercial type-B gelatines. J Photochem Photobiol A 2004; 163:537-546.

16. Millington KR, Maurdev G, Jones MJ. The thermal Chemiluminescence of fibrous proteins. Polym Degrad Stab 2007;92:1505-12.

17. Rychlý J, Rychlá L. Chemiluminescence from polymers. In: Strlič M, Kolar J, editors. Ageing and stabilisation of paper. Ljubljana: National and University Library; 2005, pp 71-90. 